\title{
Prognostic significance of expression of epithelial-mesenchymal transition driver brachyury in breast cancer and its association with subtype and characteristics
}

\author{
KWAN HO LEE ${ }^{1}$, EUN YOUNG KIM ${ }^{1}$, JI SUP YUN ${ }^{1}$, YONG LAI PARK ${ }^{1}$, \\ SUNG-IM DO ${ }^{2}$, SEOUNG WAN CHAE ${ }^{2}$ and CHAN HEUN PARK ${ }^{1}$ \\ Departments of ${ }^{1}$ Surgery and ${ }^{2}$ Pathology, Kangbuk Samsung Hospital, \\ Sungkyunkwan University School of Medicine, Seoul 03181, Republic of Korea
}

Received July 13, 2017; Accepted October 13, 2017

DOI: $10.3892 / 01.2017 .7402$

\begin{abstract}
Brachyury is a T-box transcription factor characterized as a driver of the epithelial-to-mesenchymal process, which is associated with poor prognosis of patients with breast cancer. The present study investigated expression of brachyury in breast cancer including primary tumor, metastatic and recurred tumor tissues, and the clinical significance and value of brachyury as a prognostic biomarker. This retrospective study included a series of 102 consecutive patients surgically resected between January 2005 and December 2011. Brachyury expression in tumor cell was evaluated using immunohistochemistry and scored as the immunoactivity. Of 102 patients, 62 primary tumors were positive for brachyury expression and 40 were negative. Multivariate analysis of disease-free survival (DFS) revealed brachyury expression, HER2 and lymphovascular invasion as independent prognostic factors [brachyury negative vs. positive hazard ratio (HR), 3.0; $\mathrm{P}=0.024$; HER2 negative vs. positive $\mathrm{HR}, 4.9 ; \mathrm{P}=0.003$; lymphovascular invasion absent vs. present $\mathrm{HR}, 3.5 ; \mathrm{P}=0.020]$.
\end{abstract}

Correspondence to: Dr Sung-Im Do, Department of Pathology, Kangbuk Samsung Hospital, Sungkyunkwan University School of Medicine, 29 Saemunan-ro, Jongno, Seoul 03181, Republic of Korea E-mail: sungim.do@samsung.com

Dr Chan Heun Park, Department of Surgery, Kangbuk Samsung Hospital, Sungkyunkwan University School of Medicine, 29 Saemunan-ro, Jongno, Seoul 03181, Republic of Korea

E-mail: chanheun1@gmail.com

Abbreviations: AR, androgen receptor; CI, confidence interval; DFS, disease-free survival; EMT, epithelial-mesenchymal transition; ER, estrogen receptor; HER2, human epidermal growth factor receptor 2; HR, hazard ratio; HRP, horseradish peroxidase; $\mathrm{H} \& \mathrm{E}$, hematoxylin and eosin; IHC, immunohistochemical; OS, overall survival; PR, progesterone receptor; TMA, tissue microarray analysis; TNBC, triple-negative breast cancer

Key words: brachyury, epithelial-mesenchymal transition, breast cancer, triple-negative breast cancer, microcalcification
These results were particularly observed in triple-negative breast cancer (TNBC), no recurrence or mortality occurred in brachyury negative group during the follow-up period, and therefore a significantly improved prognosis was demonstrated in these patients compared with the brachyury positive group [overall survival (OS), $\mathrm{P}=0.022$; DFS, $\mathrm{P}=0.002$ ]. Brachyury expression in metastatic lymph node/recurred tumors was not significantly associated with prognosis $(\mathrm{OS}, \mathrm{P}=0.745$; $\mathrm{DFS}, \mathrm{P}=0.189)$. Therefore, Brachyury expression in primary tumor independently is a potential predictor of poor prognosis, particularly in TNBC, where it appears to serve a crucial function in recurrence and mortality. Brachyury vaccines under clinical trials are likely to be useful in patients with breast cancer.

\section{Introduction}

The epithelial-to-mesenchymal transition (EMT) is a process in which cells lose epithelial properties and acquire the properties of mesenchymal cells. This is a normal developmental process in the early embryo, but is also a feature of tumor cells $(1,2)$. EMT is crucial in the development of more invasive metastatic tumors and the acquisition of resistance to anticancer therapies (3-5).

Brachyury is a member of the T-box family of transcription factors and is a highly conserved cellular protein. It functions in the EMT process during cancer progression and is involved in fetal mesoderm formation $(6,7)$. High expression of brachyury is associated with an increased likelihood of recurrence and distant metastasis, invasion to the extracellular matrix and development of resistance to chemotherapy (7-12). Thus, brachyury has been implicated as a tool for predicting tumor characteristics and prognosis. However, only a limited number of studies have addressed the correlation between brachyury expression and survival outcome in patients with breast cancer.

Triple-negative breast cancer (TNBC) features the deleterious expression of receptors, including estrogen receptor (ER), progesterone receptor (PR) and human epidermal growth factor receptor 2 (HER2). Effective treatment of TNBC is difficult, whereby recurrence and mortality rates are increased 
compared with other subtypes of breast cancer (13-15). EMT markers are highly expressed in TNBC cells, suggesting an association between poor prognosis of TNBC and EMT $(16,17)$.

Although lymphatic permeation is an important route for breast cancer progression, to the best of our knowledge, only two studies have addressed the involvement of brachyury in lymph node metastasis $(18,19)$. Data are limited concerning expression of brachyury in recurrent tumors; however, these data may be important in identifying patients for which the brachyury vaccine, currently in clinical trials, is expected to be of therapeutic benefit (20).

The present study investigated the expression of brachyury in breast cancer tissues, including primary tumor, axillary metastatic lymph nodes and recurrent tumor. The clinical significance and value of brachyury as a biomarker to predict tumor recurrence or survival in patients with breast cancer was then explored. In addition, the association between expression of brachyury and tumor characteristics was evaluated to understand its biological behavior.

\section{Materials and methods}

Patients. The present retrospective study included consecutive patients with breast cancer surgically resected at Kangbuk Samsung Hospital (Seoul, Korea), between January 2005 and December 2011. The 102 patients whose surgical samples were available consisted of 102 primary tumors, 21 metastatic axillary lymph nodes and 15 recurrent tumors. Primary invasive ductal carcinoma, not otherwise specific tissue, metastatic cancer tissue from lymph nodes and recurrent tumor tissue was obtained for tissue microarray analysis (TMA). Specimens were fixed using 10\% formalin solution at room temperature for $24 \mathrm{~h}$ and embedded in paraffin using a standard protocol. Tissue sections ( $3 \mu \mathrm{m}$ thick) were stained using hematoxylin (at room temperature for $90 \mathrm{sec}$ ) and eosin (at room temperature for $40 \mathrm{sec}$ ) using a Dako Coverstainer fully automated system (Dako; Agilent Technologies, Inc., Santa Clara, CA, USA). Hematoxylin and eosin (H\&E) stained slides from all patients were reviewed by two pathologists (Dr Sung-Im Do and Dr Seoung Wan Chae, of the Department of Pathology, Kangbuk Samsung Hospital, Seoul, Korea) in a blinded manner with an Olympus BX51 light microscope, at x200 magnification, to confirm histological data, including tumor $(\mathrm{T})$ and node $(\mathrm{N})$ stage (based on the staging system by the Union for International Cancer Control/American Joint Committee on Cancer, 7th edition), (21) lymphatic invasion and other characteristics. The most representative tumor area from each $\mathrm{H} \& \mathrm{E}$ stained slide was selected and its location marked on the particular paraffin block, the most representative tissue core was obtained from each tumor specimen. TMA specimens were assembled using a tissue-array instrument (Tissue-Tek Quick-Ray; Sakura Finetek Europe B.V., Flemingweg, The Netherlands) consisting of thin-walled stainless steel punches, and stylets for emptying and transferring the needle contents. The assembly was held in an X-Y position guide with a $1-\mathrm{mm}$ increment between the individual samples, a 4-mm punch depth stop device and semi-automatic micrometers. The instrument was used to create holes in a recipient block with defined array cores. The fit needle delivered the tissue cores to the recipient block. Taking into account the limitations of the representative areas of the tumor, duplicate $2 \mathrm{~mm}$-diameter tissue cores were used from each donor block. The tissue cores taken from within the tumor represented $>70 \%$ of the material.

In addition, clinical data of the patients, including age, sex, type of operation, radiotherapy, chemotherapy and hormonal therapy were reviewed. No patients were treated for breast cancer prior to surgery. The majority of the patients (97/102) received adjuvant chemotherapy, usually anthracycline-based with or without taxane regimen. Of the 97 patients, 27 (27.8\%) were treated with an FEC regimen consisting of $500 \mathrm{mg} / \mathrm{m}^{2} 5$-Fluorouracil intravenously administered on day 1 and $100 \mathrm{mg} / \mathrm{m}^{2}$ epirubicin intravenously administered on day 1 and $500 \mathrm{mg} / \mathrm{m}^{2}$ cyclophosphamide intravenously administered on day 1 every 3 weeks for 6 cycles, and 30 (30.9\%) received an $\mathrm{AC}$ regimen consisting of $60 \mathrm{mg} / \mathrm{m}^{2}$ doxorubicin intravenously administered on day 1 and $600 \mathrm{mg} / \mathrm{m}^{2}$ cyclophophamide intravenously administered on day 1 every 3 weeks for 4 cycles, and $35(36.1 \%)$ received a sequential ACT regimen comprising 4 cycles of AC followed by 4 cycles of $100 \mathrm{mg} / \mathrm{m}^{2}$ docetaxel. In addition, all patients with ER- or PR-positive tumors took tamoxifen (20 mg once a day) prior to menopause, and aromatase inhibitor (anastrozol: $1 \mathrm{mg}$ once a day or letrozole: $2.5 \mathrm{mg}$ once a day) following menopause for 5 years unless recurrence occurred during follow-up. The patients with HER2 positive tumors who possessed $>1 \mathrm{~cm}$ tumors or were pN1-3 also received trastuzumab triweekly $(6 \mathrm{mg} / \mathrm{kg})$ for 1 year.

All patients underwent physical examination at 3-month intervals following surgery, breast ultrasonography at 6-month intervals, mammography and chest computed tomography, and bone scan and breast magnetic resonance imaging at 1-year intervals. The last follow-up date was December 31, 2016, for all available patients. Disease-free survival (DFS) was defined as the interval between the date of treatment for breast cancer and the date of evidence of recurrence events, including the following: Invasive recurrence in any sites or a novel invasive breast cancer in the contralateral breast. Overall survival (OS) was defined as the time until the time of last follow-up or of death from any cause.

The study protocol was approved by the Institutional Review Board of Kangbuk Samsung Hospital, Sungkyunkwan University of Korea on August 30, 2016 (approval no. KBSMC 2016-10-022-001).

Immunohistochemical (IHC) scoring. Scoring for each IHC marker was performed using an Olympus BX51 light microscope at x 200 magnification by an experienced breast histopathologist who was blinded to the results of other markers and patient identity. IHC analysis was performed using Leica BOND MAX ${ }^{\mathrm{TM}}$ fully automated immunohistochemistry system, according to the manufacture's protocol (Leica Microsystems GmbH, Wetzlar, Germany). Briefly, $4 \mu \mathrm{m}$ thick sections were deparaffinized and pre-treated with the Epitope Retrieval Solution 2 (EDTA buffer $\mathrm{pH} 8.8$ ) at $98^{\circ} \mathrm{C}$ for $20 \mathrm{~min}$. Once the tissue washed three times with Bond TM Wash Solution 10X concentrate (cat no. AR9590, Leica Microsystems, $\mathrm{GmbH}$ ), peroxidase blocking was performed for 10 min using the Bond Polymer Refine Detection kit DS9800 (Leica Microsystems, $\mathrm{GmbH}$ ) according to manufacturer's protocol. Tissues were again washed three times with Bond 
TM Wash Solution 10X concentrate (cat no. AR9590; Leica Microsystems, $\mathrm{GmbH}$ ) and then incubated with the primary antibodies at room temperature for $60 \mathrm{~min}$. Subsequently, tissues were incubated with bond polymer (cat no. AR9352; Leica Microsystems, $\mathrm{GmbH}$ ) at room temperature for $10 \mathrm{~min}$ and developed using 3,3-diaminobenzidine at room temperature for $10 \mathrm{~min}$. Primary antibodies used are as follows: ER (cat no. RM-9101-F; 1:200 dilution; SP1 clone; Lab Vision Corporation, Fremont, CA, USA), PR (cat no. M3569; 1:200 dilution; PgR636 clone; Dako; Agilent Technologies, Inc.) and HER2 (cat no. RM-9103-R7-A; 1:200 dilution; SP3 clone; Lab Vision Corporation) were used. For brachyury staining, human tissues obtained were fixed in $10 \%$ formalin solution at room temperature for $24 \mathrm{~h}$, dehydrated through a graded ethanol series (30, 50 and 100\%), washed in xylene and processed for embedding in paraffin wax, at room temperature and for $30 \mathrm{~min}$. Sections were incubated in a solution of $0.3 \% \mathrm{H}_{2} \mathrm{O}_{2}$ at room temperature for $15 \mathrm{~min}$ to inhibit endogenous peroxidase activity. Antigen retrieval procedure was performed using $10 \mathrm{mM}$ Tris + $1 \mathrm{mM}$ EDTA + $0.03 \%$ Tween-20 Solution at $98^{\circ} \mathrm{C}$ for $30 \mathrm{~min}$ in a presser cooker chamber. Non-specific blocking was quenched by incubation with $4 \%$ bovine serum albumin for $30 \mathrm{~min}$. Sections were then incubated for $1 \mathrm{~h}$ at room temperature with primary antibodies against brachyury (cat no ab57480; Abcam, Cambridge, UK) diluted to 1:500. The detection system EnVision+ for secondary horseradish peroxidase-conjugated mouse antibodies (cat no. K4001; 1:2,000; Dako; Agilent Technologies, Inc.) was applied according to the manufacturer's protocol. The secondary antibodies were incubated at room temperature for $8 \mathrm{~min}$. Slides were stained with liquid diaminobenzidine tetrahydrochloride, a high-sensitivity substrate-chromogen system (cat no. K5007; Dako; Agilent Technologies, Inc.). Counterstaining was performed with Meyer's hematoxylin at room temperature for $1 \mathrm{~min}$. A total of between three and five randomly selected fields were evaluated for each slide. For each field, the percentage of positive tumor cells was calculated as follows: (Number of positive tumor cells/total number of tumor cells) $\mathrm{x} 100$. Nuclear staining was scored by examining for brachyury in the nucleus. The relative staining intensity was scored as weak (+) for pale brown intensity, moderate (++) for intermediate brown intensity and strong (+++) for intense, dark brown immunoprecipitate. Brachyury score was calculated using the Allred scoring system of staining intensity (absent, 0; weak, 1; moderate, 2; and strong, 3) added to another score of the percentage of cells stained (none, $0 ;<1 \%, 1 ; 1-10 \%, 2 ; 11-33 \%$, $3 ; 34-66 \%, 4$; and $67-100 \%, 5)$ to yield a total score of 0 or $2-8$, using the Allred scoring system as previously described (22). The score was calculated as the immunoactivity observed in the nucleus and cytoplasm.

Statistical analyses. All statistical analyses were performed using R version 3.3.2 (23-25). All data were presented as the mean \pm standard deviation, or number and percentage. Associations among variables were evaluated using Fisher's exact test or $\chi^{2}$ test. Continuous variables were compared using the Wilcoxon rank-sum test. OS and DFS curves were determined using the Kaplan-Meier method with differences assessed using the log-rank test. Risk factors of DFS were analyzed by univariate analysis with the log-rank test and
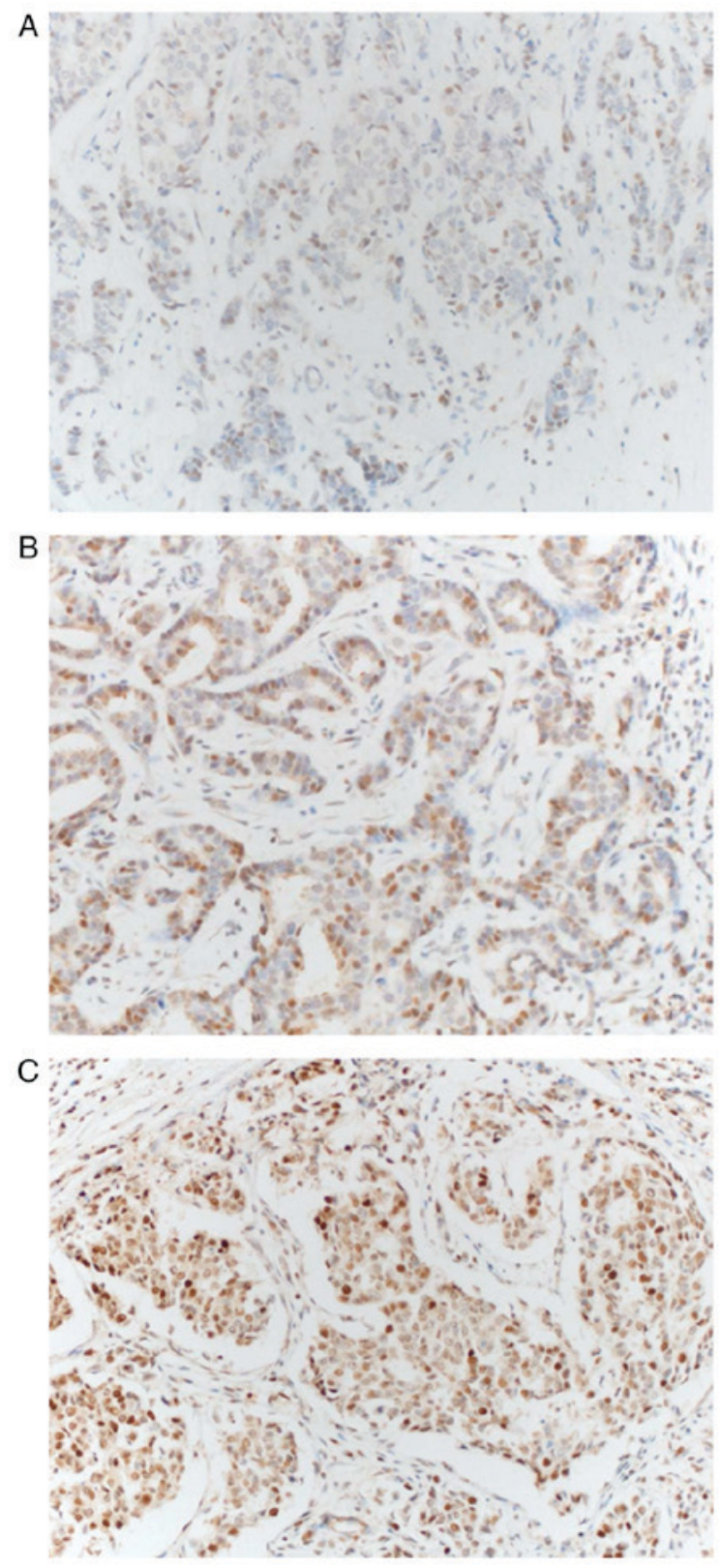

Figure 1. Immunohistochemical analysis of brachyury expression in nucleus of breast cancer. (A) Weak, (B) moderate and (C) strong expression of brachyury (magnification, x200).

multivariate analysis with Cox's proportional hazard model. All tests were two-tailed and $\mathrm{P}<0.05$ was considered to indicate a statistically significant difference.

\section{Results}

Associations between brachyury protein expression and clinicopathological factors in primary tumors. The present study consisted of 102 patients, of whom all were female. Brachyury protein expression in primary, metastatic and recurrent tumors was assessed using IHC staining. Brachyury protein expression occurred in the nucleus and cytoplasm of tumor cells (Fig. 1). Brachyury expression in the cytoplasm was observed in all tumor cells; the expression intensity varied somewhat; however, the percentage of cells stained typically exceeded $80 \%$, so that the score difference between 
Table I. Clinicopathological characteristics of the patients according to brachyury expression in nucleus of primary tumor.

\begin{tabular}{|c|c|c|c|}
\hline Parameter & Brachyury-negative $(\mathrm{n}=40)$ & Brachyury-positive ( $\mathrm{n}=62$ ) & P-value \\
\hline Age, years ${ }^{a}$ & & & 0.397 \\
\hline$\leq 45$ & $12(30.0)$ & $25(40.3)$ & \\
\hline$>45$ & $28(70.0)$ & $37(59.7)$ & \\
\hline $\mathrm{pT}^{\mathrm{a}}$ & & & 1.000 \\
\hline 1 & $17(42.5)$ & 27 (43.5) & \\
\hline $2-4$ & $23(57.5)$ & $35(56.5)$ & \\
\hline $\mathrm{pN}^{\mathrm{a}}$ & & & 0.965 \\
\hline 0 & $19(47.5)$ & $31(50.0)$ & \\
\hline $1-3$ & $21(52.5)$ & $31(50.0)$ & \\
\hline Histological grade ${ }^{a}$ & & & 0.552 \\
\hline $1-2$ & $20(50.0)$ & $36(58.1)$ & \\
\hline 3 & $20(50.0)$ & $26(41.9)$ & \\
\hline Molecular subtype $^{\mathrm{a}}$ & & & 0.316 \\
\hline Non-TNBC & $19(47.5)$ & 37 (59.7) & \\
\hline TNBC & $21(52.5)$ & $25(40.3)$ & \\
\hline Lymphovascular invasion $^{\mathrm{a}}$ & & & 0.908 \\
\hline Absent & $20(50.0)$ & $33(53.2)$ & \\
\hline Present & $20(50.0)$ & $29(46.8)$ & \\
\hline Microcalcification ${ }^{\mathrm{a}}$ & & & 0.025 \\
\hline Absent & $18(45.0)$ & $43(69.4)$ & \\
\hline Present & $22(55.0)$ & $19(30.6)$ & \\
\hline Estrogen receptor ${ }^{\mathrm{a}}$ & & & 0.052 \\
\hline Negative & $28(70.0)$ & $30(48.4)$ & \\
\hline Positive & $12(30.0)$ & $32(51.6)$ & \\
\hline Progesterone receptor ${ }^{\mathrm{a}}$ & & & 0.125 \\
\hline Negative & $30(75.0)$ & $36(58.1)$ & \\
\hline Positive & $10(25.0)$ & $26(41.9)$ & \\
\hline 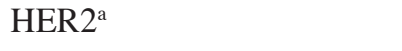 & & & 0.494 \\
\hline Negative & $32(80.0)$ & $54(87.1)$ & \\
\hline Positive & $8(20.0)$ & $8(12.9)$ & \\
\hline Type of surgery ${ }^{a}$ & & & 1.000 \\
\hline Conserving surgery & $5(12.5)$ & $7(11.3)$ & \\
\hline Total mastectomy & $35(87.5)$ & $55(88.7)$ & \\
\hline Follow up periods, months ${ }^{\mathrm{b}}$ & $79.2 \pm 35.2$ & $82.2 \pm 42.8$ & 0.712 \\
\hline Radiotherapy $^{\mathrm{a}}$ & & & 0.526 \\
\hline No & $30(75.0)$ & $51(82.3)$ & \\
\hline Yes & $10(25.0)$ & $11(17.7)$ & \\
\hline Chemotherapy $^{\mathrm{a}}$ & & & 0.665 \\
\hline No & $1(2.5)$ & $4(6.5)$ & \\
\hline Yes & $39(97.5)$ & 58 (93.5) & \\
\hline Cytoplasmic brachyury ${ }^{\mathrm{a}}$ & & & 0.069 \\
\hline Low & $23(57.5)$ & $23(37.1)$ & \\
\hline High & $17(42.5)$ & 39 (62.9) & \\
\hline
\end{tabular}

${ }^{a}$ Data are presented as $\mathrm{n}(\%)$. ${ }^{\mathrm{b}}$ Data are presented as the mean \pm standard deviation. TNBC, triple-negative breast cancer; HER2, human epidermal growth factor receptor 2 . 

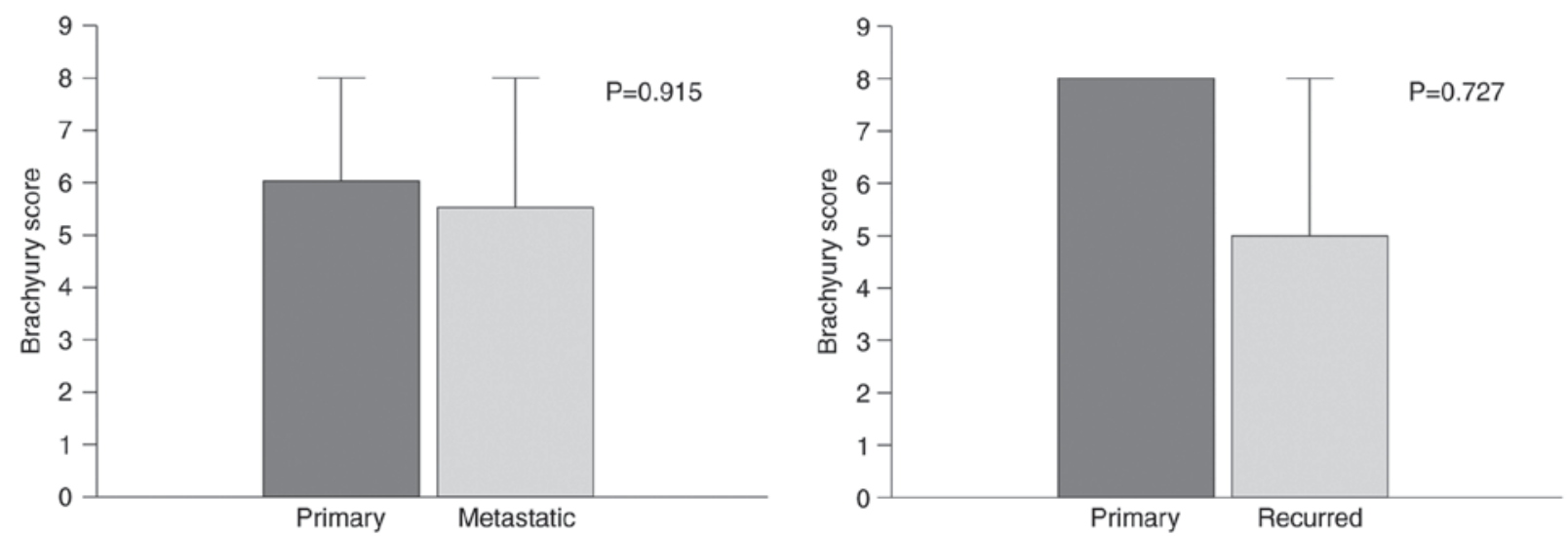

Figure 2. Comparison of nuclear brachyury protein expression between primary and metastatic lymph nodes, and primary and recurred tumor

the tumors was small (range, 5-8). Depending on the presence or absence of brachyury expression in the nucleus, the study population was divided into a brachyury negative group $(n=40)$ or a brachyury positive group $(n=62)$ to compare the differences in clinicopathological characteristics (Table I). Based on the median value of brachyury expression in the cytoplasm 5-6 points were defined as low brachyury and 7-8 as high brachyury. In the brachyury-positive group, $\mathrm{ER}+$ and PR+ tumors were more prevalent; however, neither were significant. Microcalcification in tumors was significantly associated with brachyury expression $(\mathrm{P}=0.025)$. The brachyury-positive group possessed a high score, even in the cytoplasm; however, without statistical significance $(\mathrm{P}=0.069)$. The remaining clinicopathological factors did not demonstrate any statistical differences.

Differences in nuclear brachyury expression between primary and metastatic or recurrent tumors. Brachyury staining of primary tumor samples was performed in samples from 15 patients with recurrent tumors that were available for immunostaining. The difference in scores was compared between primary and recurrent tumors. Differences between 21 metastatic lymph nodes and primary tumors were similarly compared. The comparisons did not identify any statistically significant differences (primary vs. metastatic, $\mathrm{P}=0.915$; primary vs. recurred, $\mathrm{P}=0.727$; Fig. 2).

Association between nuclear brachyury expression in primary tumors and postoperative prognoses of patients. The effect of brachyury expression in primary tumors on the prognosis of patients was investigated. Following a median follow-up of 73.5 months (range, 2-145 months), 25 patients experienced relapse and 9 patients succumbed. The 5-year DFS and OS rates were 84.3 and $92.2 \%$, respectively. OS and DFS appeared to decrease in the brachyury negative group, compared with the positive; however, no statistical significance was identified [OS hazard ratio (HR), 1.4; 95\% confidence interval (CI), 0.34-5.47; $\mathrm{P}=0.656$ and DFS HR, 2.2; 95\% CI, 0.89-5.56; $\mathrm{P}=0.081$; data not shown]. Cox's proportional hazard regression models of DFS revealed that the presence of lymph node metastasis, lymphovascular invasion and HER2 positivity were associated with poor prognosis, whereas no factor was significantly associated with an improved prognosis (Table II).
Multivariate analysis that included variables with $\mathrm{P}<0.2$ in univariate regression analysis revealed brachyury expression in the nucleus of primary tumor, HER2 and lymphovascular invasion as independent prognostic factors for DFS (brachyury negative versus positive, HR 3.0, $\mathrm{P}=0.024$; HER 2 negative vs. positive $\mathrm{HR}, 4.9 ; \mathrm{P}=0.003$ and lymphovascular invasion absent vs. present HR, 3.5; $\mathrm{P}=0.020$; Table II).

The hypothesis of the present study was that the expression of brachyury is associated with poor outcome of patients with TNBC based on a previous study (19). The prognoses of patients with TNBC $(n=46)$ and those with non-TNBC $(n=56)$ were examined separately. In the brachyury negative group in TNBC, no recurrence or mortalities occurred during the follow-up period, and therefore a significantly improved prognosis was identified in these patients compared with the brachyury-positive group $(\mathrm{OS}, \mathrm{P}=0.022$; DFS, $\mathrm{P}=0.002$; Fig. 3A). No statistical difference was observed in those with non-TNBC (OS HR, 0.8; 95\% CI, 0.02-2.94; $\mathrm{P}=0.247$ and DFS HR, 1.4 ; 95\% CI, 0.46-4.49; P=0.537; Fig. 3B).

Association between nuclear brachyury protein expression in metastatic/recurrent tumors and postoperative prognoses of patients. No significant differences in the degree of brachyury expression in the primary tumor and metastatic/recurrent tumor were identified in the present study. The way in which brachyury expression in metastatic and recurrent tumors affected survival was investigated. Among the patients with lymph node metastasis observed at the first surgery, 23 samples were able to be stained. Out of the patients with recurrence during follow-up, 22 samples were able to be stained and were grouped together with lymph node metastasis samples $(n=45)$. There were $14(31 \%)$ brachyury positive tumors and 31 $(69 \%)$ brachyury negative tumors. The groups demonstrated no significant difference in OS or DFS (OS HR, 1.2; 95\% CI, 0.38-3.91; $\mathrm{P}=0.745$ and DFS HR, 1.6; 95\% CI, 0.69-3.54; $\mathrm{P}=0.281$; Fig. 4). It was intended that the subgroups of patients with TNBC were to be analyzed; however, the small number of samples did not allow for this.

Analysis of differences in survival rates with cytoplasmic brachyury expression. Brachyury score in the cytoplasm ranged between 5 and 8 as expression of cytoplasmic brachyury was exhibited by $>80 \%$ of all stained cells, with the only differences 
Table II. Univariate and multivariate analyses of disease free survival of patients with breast cancer.

\begin{tabular}{|c|c|c|c|c|}
\hline \multirow[b]{2}{*}{ Parameter } & \multicolumn{2}{|c|}{ Univariate } & \multicolumn{2}{|c|}{ Multivariate } \\
\hline & $\mathrm{HR}(95 \% \mathrm{CI})$ & P-value & HR $(95 \%$ CI $)$ & P-value \\
\hline \multicolumn{5}{|l|}{ Age, years } \\
\hline$\leq 45$ & ref & & & \\
\hline$>45$ & $0.990(0.440-2.200)$ & 0.973 & & \\
\hline \multicolumn{5}{|l|}{ pT stage } \\
\hline 1 & ref & & & \\
\hline $2-4$ & $2.170(0.910-5.190)$ & 0.082 & $2.419(0.882-6.632)$ & 0.086 \\
\hline \multicolumn{5}{|l|}{ pN stage } \\
\hline 0 & ref & & & \\
\hline $1-3$ & $2.420(1.040-5.610)$ & 0.040 & $1.394(0.498-3.902)$ & 0.527 \\
\hline \multicolumn{5}{|c|}{ Histologic grade } \\
\hline $1-2$ & ref & & & \\
\hline 3 & $1.880(0.850-4.140)$ & 0.119 & $1.345(0.587-3.082)$ & 0.483 \\
\hline \multicolumn{5}{|c|}{ Microcalcification } \\
\hline Absent & ref & & & \\
\hline Present & $1.050(0.470-2.330)$ & 0.909 & & \\
\hline \multicolumn{5}{|l|}{$\mathrm{L} / \mathrm{V}$ invasion } \\
\hline Absent & ref & & & \\
\hline Present & $4.360(1.740-10.920)$ & 0.002 & 3.481 (1.214-9.977) & 0.020 \\
\hline \multicolumn{5}{|l|}{ Surgery type } \\
\hline $\mathrm{BCS}$ & ref & & & \\
\hline Mastectomy & $3.440(0.470-25.440)$ & 0.226 & & \\
\hline \multicolumn{5}{|c|}{ Estrogen receptor } \\
\hline Negative & ref & & & \\
\hline Positive & $0.610(0.270-1.390)$ & 0.239 & & \\
\hline \multicolumn{5}{|c|}{ Progesterone receptor } \\
\hline Negative & ref & & & \\
\hline Positive & $0.480(0.190-1.220)$ & 0.123 & $0.787(0.289-2.148)$ & 0.641 \\
\hline \multicolumn{5}{|l|}{ HER 2} \\
\hline Negative & ref & & & \\
\hline Positive & $2.950(1.270-6.840)$ & 0.012 & $4.889(1.694-14.110)$ & 0.003 \\
\hline \multicolumn{5}{|c|}{ Brachyury (nucleus) } \\
\hline Negative & ref & & & \\
\hline Positive & $2.220(0.890-5.560)$ & 0.089 & $3.004(1.157-7.804)$ & 0.024 \\
\hline \multicolumn{5}{|c|}{ Brachyury (cytoplasm) } \\
\hline Low & ref & & & \\
\hline High & $0.880(0.400-1.920)$ & 0.741 & & \\
\hline
\end{tabular}

observed being in staining intensity. Therefore, the samples were divided into low (5-6 points) brachyury expression and high (7-8 points) expression groups to investigate the effect of brachyury expression in the cytoplasm on patient prognosis. This analysis was also divided into TNBC and non-TNBC according to molecular subtype, since brachyury expression in the cytoplasm did not correlate with prognosis in the previous Cox's proportional hazard regression models. No statistical significance was evident between the high and low group, regardless of the molecular subtype (TNBC OS, $\mathrm{P}=0.996$; DFS, $\mathrm{P}=0.228$ and non-TNBC OS, $\mathrm{P}=0.12$; DFS, $\mathrm{P}=0.533$ ).

\section{Discussion}

Brachyury has been associated with cancer cell invasion, metastatic progression and chemoresistance (7-12). Thus, the present study investigated the effects of brachyury expression on the prognosis of patients with breast cancer, whilst also exploring the expression of brachyury in recurrent and metastatic tumors, addressed in only two prior studies $(19,20)$, to the best of our knowledge. The present study is, to the best of our knowledge, the first to demonstrate the association between brachyury expression in recurrent and metastatic tumors, and prognosis. 
A

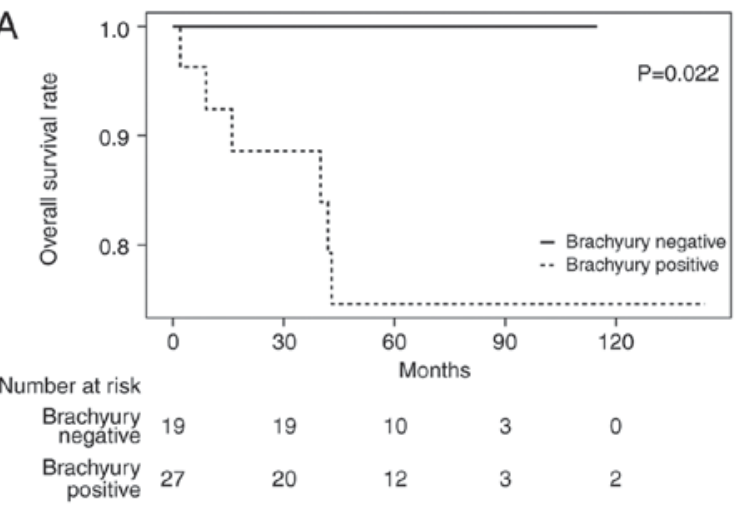

B

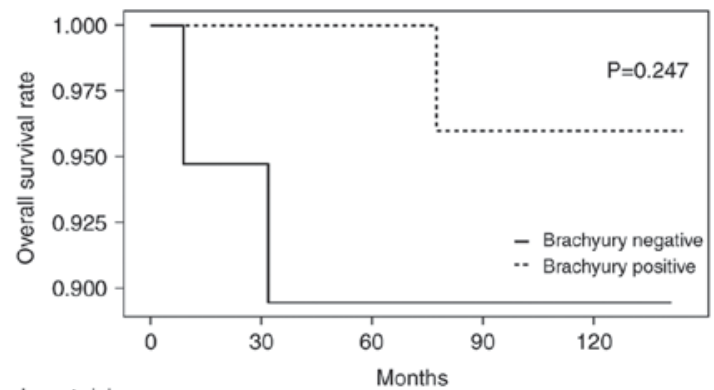

Number at risk

$\begin{array}{rrrrrr}\begin{array}{r}\text { Brachyury } \\ \text { negative }\end{array} & 19 & 18 & 116 & 11 & 4 \\ \begin{array}{r}\text { Brachyury } \\ \text { positive }\end{array} & 37 & 35 & 30 & 23 & 12\end{array}$

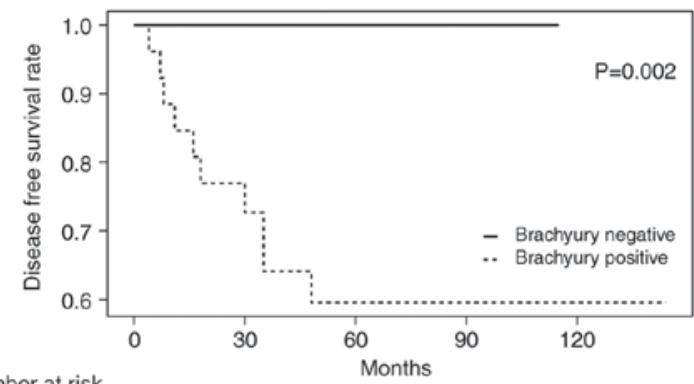

Number at risk

$\begin{array}{clllll}\begin{array}{c}\text { Brachyury } \\ \text { negative }\end{array} & 19 & 19 & 10 & 3 & 0\end{array}$

$\begin{array}{cccccc}\begin{array}{c}\text { Brachyury } \\ \text { positive }\end{array} & 27 & 18 & 11 & 3 & 2\end{array}$

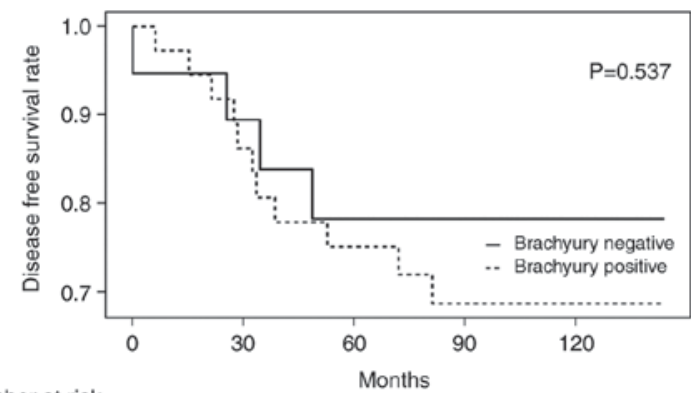

Number at risk

$\begin{array}{cccccc}\begin{array}{c}\text { Brachyury } \\ \text { negative }\end{array} & 19 & 17 & 13 & 9\end{array}$

$\begin{array}{llllll}\text { Brachyury } & 37 & 31 & 27 & 20 & 9\end{array}$

Figure 3. Brachyury expression in the nucleus of primary tumor and prognosis. Kaplan-Meier estimates of overall survival and disease-free survival in: (A) 46 cases of TNBC classified based on the brachyury expression (positive group vs. negative group), and (B) 56 cases of non-TNBC classified based on the brachyury expression (positive group vs. negative group). TNBC, triple negative breast cancer.
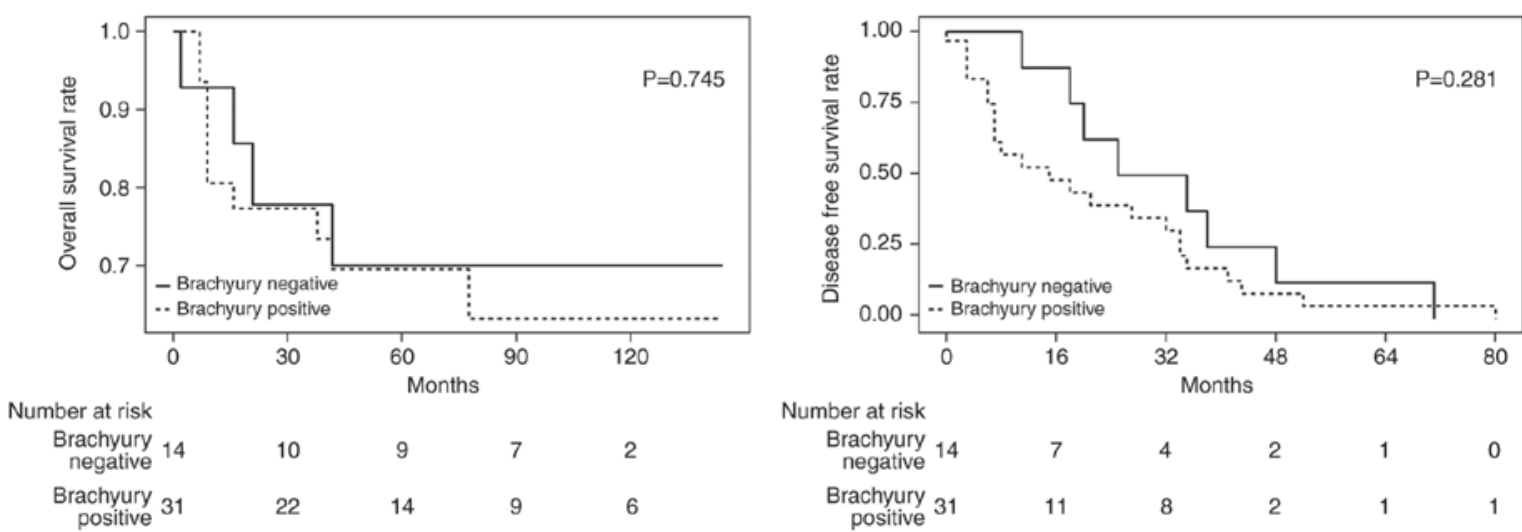

Figure 4. Brachyury expression in nucleus of metastatic tumor and prognosis. Kaplan-Meier estimates of overall survival and disease-free survival in 45 cases of breast cancer classified based on the brachyury expression (positive group vs. negative group).

Brachyury has been increasingly studied as a targeting protein of interest in immune therapy $(19,20)$. Previous studies have demonstrated that brachyury expression is prognostic only in TNBC (18). In the present study, all recurrences or mortalities in TNBC occurred in the brachyury-positive group, while no recurrence or mortalities occurred during the follow-up period in the brachyury-negative group. These results contribute toward increased anticipation of the results from ongoing clinical trials of a brachyury vaccine as a potential treatment for TNBC. However, why brachyury is more relevant to tumor prognosis in TNBC is not clear, and should be addressed in further studies of the association of brachyury with other factors and associated signaling pathways. This may allow for the selection of the most appropriate patient group for brachyury targeted therapy and to investigate the synergistic effects of the combination therapy with other drugs.

Presently, brachyury expression was not statistically associated with molecular subtype, including PR and HER2. ER positivity had a marginally statistically significant association $(\mathrm{P}=0.052)$, in contrast with previous studies $(18,19)$. The association of these biomarkers remains a subject of debate, with dichotomous results from different studies. The relevance of these biomarkers requires further investigation. 
A previous study examined stained tissue for the presence of brachyury in the cytoplasm of breast tumor cells and brachyury expression in tumors was calculated as the sum of the brachyury expression in the nucleus and cytoplasm (19). In the present study, unlike previous studies, each cytoplasm and nucleus were separately analyzed for prognosis. Expression in the nucleus was significantly associated with a poor prognosis, whereas expression in cytoplasm was not significantly associated with prognosis. The reasons for these outcomes may be hypothesized using other studies about breast cancer. In a study of the androgen receptor (AR), AR without ligand which attached to heat shock proteins is present mainly in the cytoplasm. In the presence of ligand, the ligand-binding domain is unbound from heat shock protein and becomes active in translocating into the nucleus (26). A similar phenomenon may be envisaged for brachyury. In support of this hypothesis, in the present study, brachyury expression in the cytoplasm was observed in all stained samples, compared with expression in the nucleus being observed in only $60.8 \%$ of the samples. The effect of expression in the cytoplasm and nucleus on prognosis was different. Thus, as demonstrated with the AR, any receptor that responds to brachyury antibody may serve a function in chemoresistance, tumor invasiveness and metastasis if it is activated and translocated into the nucleus.

The exact mechanism by which microcalcification forms in breast cancer is not understood. Previous studies have revealed that microcalcification appears in tumor cells in a manner similar to that occurring in physiological phenomena $(27,28)$. Cells involved in bone development, such as osteoblasts and hypertrophic chondrocytes, are mineralization-competent cells with a mesenchymal origin (29,30). Thus, microcalcification may form by mesenchymal cells that are translocated while the EMT process takes place in tumor cells (31). In the present study, microcalcification was significantly more frequent in tumors expressing the EMT driver, brachyury. This result may assist in validating the hypothesis of previous studies.

Understand is limited about the expression of brachyury in metastatic lymph nodes. a previous study compared the level of brachyury expression in primary and metastatic cancer in 115 patients with lung cancer and identified increased expression in metastatic lymph nodes compared with primary cancer (22). In addition, brachyury expression in metastatic lymph nodes suggested a poor prognosis as in primary tumors. The authors suggested two explanations for the abundant expression of brachyury in metastatic lymph nodes. First, expression of brachyury in primary tumors enhances the metastatic and invasive ability, which in turn metastasizes into lymph nodes. Second, expression of brachyury in metastatic lymph node is increased in one of the preparations to form the so-called pre-metastatic niche. In addition, mesenchymal markers, including snail family transcriptional repressor 2 and interleukin- 8 were increased in these metastatic lymph nodes, whereas the epithelial marker E-cadherin was decreased. In another study of 42 patients with breast cancer, increased EMT-associated genes (twist family BHLH transcription factor 1 and snail family transcriptional repressor 1 and 2) in metastatic lymph nodes were associated with poor prognosis (32).

To the best of our knowledge, the present study is the first to compare the expression of brachyury in primary breast carcinoma and metastatic lymph nodes in patients with breast cancer, and the first study to compare the effects of brachyury expression in metastatic lymph nodes on prognosis. However, unlike one previous study of lung cancer (22), the expression of brachyury in metastatic lymph nodes did not differ from the expression in primary tumor and did not demonstrate any association with prognosis. It may be that the metastatic mechanism of breast cancer is different from other types of cancer, or it may be an error caused by a small number of samples. Further studies will assist to clarify this argument.

In conclusion, the present study demonstrated that expression of brachyury in the nucleus of primary tumor possesses value as an independent marker that predicts poor prognosis. This was particularly evident in TNBC, where no recurrence or mortalities occurred in the brachyury negative group during the follow-up period. In other words, all recurrences or mortalities only occurred in the brachyury positive group. The expression of brachyury in the metastatic or recurrent site was not different from that of the primary tumor, and there was no prognostic value. Current clinical trials of brachyury targeting vaccines are likely to be of use in patients with TNBC, although this potential should be demonstrated by a well-designed randomized prospective trial.

\section{Acknowledgements}

The present study was supported by the Medical Research Funds from Kangbuk Samsung Hospital.

\section{References}

1. Thiery JP and Sleeman JP: Complex networks orchestrate epithelial-mesenchymal transitions. Nat Rev Mol Cell Biol 7: 131-142, 2006.

2. Kalluri R and Weinberg RA: The basics of epithelial-mesenchymal transition. J Clin Invest 119: 1420-1428, 2009.

3. Thiery JP: Epithelial-mesenchymal transitions in tumour progression. Nat Rev Cancer 2: 442-454, 2002.

4. Polyak K and Weinberg RA: Transitions between epithelial and mesenchymal states: Acquisition of malignant and stem cell traits. Nat Rev Cancer 9: 265-273, 2009.

5. Singh A and Settleman J: EMT, cancer stem cells and drug resistance: An emerging axis of evil in the war on cancer. Oncogene 29: 4741-4751, 2010.

6. Larocca C, Cohen JR, Fernando RI, Huang B, Hamilton DH and Palena C: An autocrine loop between TGF- $\beta 1$ and the transcription factor brachyury controls the transition of human carcinoma cells into a mesenchymal phenotype. Mol Cancer Ther 12: 1805-1815, 2013.

7. Fernando RI, Litzinger M, Trono P, Hamilton DH, Schlom J and Palena C: The T-box transcription factor Brachyury promotes epithelial-mesenchymal transition in human tumor cells. J Clin Invest 120: 533-544, 2010.

8. Rowley M, Grothey E and Couch FJ: The role of Tbx2 and Tbx3 in mammary development and tumorigenesis. J Mammary Gland Biol Neoplasia 9: 109-118, 2004.

9. Sinclair CS, Adem C, Naderi A, Soderberg CL, Johnson M, Wu K, Wadum L, Couch VL, Sellers TA, Schaid D, et al: TBX2 is preferentially amplified in BRCA1- and BRCA2-related breast tumors. Cancer Res 62: 3587-3591, 2002.

10. Wang B, Lindley LE, Fernandez-Vega V, Rieger ME, Sims AH and Briegel KJ: The T box transcription factor TBX2 promotes epithelial-mesenchymal transition and invasion of normal and malignant breast epithelial cells. PLoS One 7: e41355, 2012.

11. Rodriguez M, Aladowicz E, Lanfrancone L and Goding CR: Tbx3 represses E-cadherin expression and enhances melanoma invasiveness. Cancer Res 68: 7872-7881, 2008.

12. Huang B, Cohen JR, Fernando RI, Hamilton DH, Litzinger MT, Hodge JW and Palena C: The embryonic transcription factor Brachyury blocks cell cycle progression and mediates tumor resistance to conventional antitumor therapies. Cell Death Dis 4: e682, 2013. 
13. Carey LA, Perou CM, Livasy CA, Dressler LG, Cowan D, Conway K, Karaca G, Troester MA, Tse CK, Edmiston S, et al: Race, breast cancer subtypes, and survival in the Carolina Breast Cancer Study. JAMA 295: 2492-2502, 2006.

14. Dent R, Trudeau M, Pritchard KI, Hanna WM, Kahn HK, Sawka CA, Lickley LA, Rawlinson E, Sun P and Narod SA: Triple-negative breast cancer: Clinical features and patterns of recurrence. Clin Cancer Res 13: 4429-4434, 2007.

15. Haffty BG, Yang Q, Reiss M, Kearney T, Higgins SA, Weidhaas J, Harris L, Hait W and Toppmeyer D: Locoregional relapse and distant metastasis in conservatively managed triple negative early-stage breast cancer. J Clin Oncol 24: 5652-5657, 2006.

16. Jeong H, Ryu YJ, An J,Lee Y and Kim A: Epithelial-mesenchymal transition in breast cancer correlates with high histological grade and triple-negative phenotype. Histopathology 60: E87-E95, 2012.

17. Sarrió D, Rodriguez-Pinilla SM, Hardisson D, Cano A, Moreno-Bueno G and Palacios J: Epithelial-mesenchymal transition in breast cancer relates to the basal-like phenotype. Cancer Res 68: 989-997, 2008.

18. Palena C, Roselli M, Litzinger MT, Ferroni P, Costarelli L, Spila A, Cavaliere F, Huang B, Fernando RI, Hamilton DH, et al: Overexpression of the EMT driver brachyury in breast carcinomas: Association with poor prognosis. J Natl Cancer Inst 106: dju054, 2014

19. Hamilton DH, Roselli M, Ferroni P, Costarelli L, Cavaliere F, Taffuri M, Palena C and Guadagni F: Brachyury, a vaccine target, is overexpressed in triple-negative breast cancer. Endocr Relat Cancer 23: 783-796, 2016.

20. Heery CR, Singh BH, Rauckhorst M, Marte JL, Donahue RN, Grenga I, Rodell TC, Dahut W, Arlen PM, Madan RA, et al: Phase I Trial of a Yeast-Based Therapeutic Cancer Vaccine (GI-6301) targeting the transcription factor brachyury. Cancer Immunol Res 3: 1248-1256, 2015.

21. Edge SB and Compton CC: American Joint Committee on Cancer: The 7th edition of the AJCC cancer staging manual and the future of TNM. Ann Surg Oncol 17: 1471-1474, 2010.

22. Shimamatsu S, Okamoto T, Haro A, Kitahara H, Kohno M, Morodomi Y, Tagawa T, Okano S, Oda Y and Maehara Y Prognostic significance of expression of the epithelial-mesenchymal transition-related factor brachyury in intrathoracic lymphatic spread of non-small cell lung cancer. Ann Surg Oncol 23 (Suppl 5): S1012-S1020, 2016.
23. R Development Core Team: R: A Language and Environment for Statistical Computing. The R Foundation for Statistical Computing, Vienna, 2011. http://www.R-project.org/.

24. Therneau TM:Survival:Survival Analysis.R package version 2.38, 2015. https://CRAN.R-project.org/package=survival.

25. Therneau TM and Grambsch PM: Modeling survival data: Extending the Cox model. Springer, New York, NY, 2010.

26. Kono M, Fujii T, Lim B, Karuturi MS, Tripathy D and Ueno NT: Androgen receptor function and androgen receptor-targeted therapies in breast cancer: A Review. JAMA Oncol 3: 1266-1273, 2017.

27. Kirsch T: Determinants of pathological mineralization. Curr Opin Rheumatol 18: 174-180, 2006.

28. Cox RF, Jenkinson A, Pohl K, O'Brien FJ and Morgan MP Osteomimicry of mammary adenocarcinoma cells in vitro increased expression of bone matrix proteins and proliferation within a 3D collagen environment. PLoS One 7: e41679, 2012.

29. Soltanoff CS, Yang S, Chen W and Li YP: Signaling networks that control the lineage commitment and differentiation of bone cells. Crit Rev Eukaryot Gene Expr 19: 1-46, 2009.

30. Anderson HC: Vesicles associated with calcification in the matrix of epiphyseal cartilage. J Cell Biol 41: 59-72, 1969.

31. Scimeca M, Giannini E, Antonacci C, Pistolese CA, Spagnoli LG and Bonanno E: Microcalcifications in breast cancer: An active phenomenon mediated by epithelial cells with mesenchymal characteristics. BMC Cancer 14: 286, 2014.

32. Markiewicz A, Ahrends T, Wełnicka-Jaśkiewicz M, Seroczyńska B, Skokowski J, Jaśkiewicz J, Szade J, Biernat W and Zaczek AJ: Expression of epithelial to mesenchymal transition-related markers in lymph node metastases as a surrogate for primary tumor metastatic potential in breast cancer. J Transl Med 10: 226, 2012.

This work is licensed under a Creative Commons

Attribution-NonCommercial-NoDerivatives 4.0 International (CC BY-NC-ND 4.0) License. 